\title{
Recent national trends in Salvia divinorum use and substance-use disorders among recent and former Salvia divinorum users compared with nonusers
}

\author{
This article was published in the following Dove Press journal: \\ Substance Abuse and Rehabilitation \\ | April 201 | \\ Number of times this article has been viewed
}

\section{Li-Tzy Wu' \\ George E Woody ${ }^{2}$ \\ Chongming Yang ${ }^{3}$ \\ Jih-Heng $\mathrm{Li}^{4}$ \\ Dan G Blazer'}

'Department of Psychiatry and Behavioral Sciences, Duke University Medical Center, Durham, NC, USA; ${ }^{2}$ Department of Psychiatry, University of Pennsylvania and Treatment Research Institute, Philadelphia, Institute, Duke University, Durham, NC, USA; ${ }^{4}$ College of Pharmacy, Kaohsiung Medical University, Kaohsiung, Taiwan PA, USA; ${ }^{3}$ Social Science Research

\footnotetext{
Correspondence: Li-Tzy Wu Department of Psychiatry and Behavioral Sciences, Duke University School of Medicine, Duke University Medical Center, Box 3419, Durham, NC 277I0, USA

$\mathrm{Tel}+\mathrm{I} 9196686067$

Fax +19196685418

Email litzy.wu@duke.edu
}

\begin{abstract}
Context: Media and scientific reports have indicated an increase in recreational use of Salvia divinorum. Epidemiological data are lacking on the trends, prevalence, and correlates of $S$. divinorum use in large representative samples, as well as the extent of substance use and mental health problems among $S$. divinorum users.
\end{abstract}

Objective: To examine the national trend in prevalence of $S$. divinorum use and to identify sociodemographic, behavioral, mental health, and substance-use profiles of recent (past-year) and former users of $S$. divinorum.

Design: Analyses of public-use data files from the 2006-2008 United States National Surveys on Drug Use and Health $(\mathrm{N}=166,453)$.

Setting: Noninstitutionalized individuals aged 12 years or older were interviewed in their places of residence.

Main measures: Substance use, S. divinorum, self-reported substance use disorders, criminality, depression, and mental health treatment were assessed by standardized survey questions administered by the audio computer-assisted self-interviewing method.

Results: Among survey respondents, lifetime prevalence of $S$. divinorum use had increased from $0.7 \%$ in 2006 to $1.3 \%$ in 2008 (an $83 \%$ increase). S. divinorum use was associated with ages 18-25 years, male gender, white or multiple race, residence of large metropolitan areas, arrests for criminal activities, and depression. S. divinorum use was particularly common among recent drug users, including users of lysergic acid diethylamide (53.7\%), ecstasy (30.1\%), heroin (24.2\%), phencyclidine (22.4\%), and cocaine (17.5\%). Adjusted multinomial logistic analyses indicated polydrug use as the strongest determinant for recent and former $S$. divinorum use. An estimated $43.0 \%$ of past-year $S$. divinorum users and $28.9 \%$ of former $S$. divinorum users had an illicit or nonmedical drug-use disorder compared with $2.5 \%$ of nonusers. Adjusted logistic regression analyses showed that recent and former $S$. divinorum users had greater odds of having past-year depression and a substance-use disorder (alcohol or drugs) than past-year alcohol or drug users who did not use $S$. divinorum.

Conclusion: S. divinorum use is prevalent among recent or active drug users who have used other hallucinogens or stimulants. The high prevalence of substance use disorders among recent $S$. divinorum users emphasizes the need to study health risks of drug interactions.

Keywords: alcohol-use disorders, drug-use disorders, ecstasy, lysergic acid diethylamide, major depression, multiple race, nicotine dependence, phencyclidine, prescription drug abuse

\section{Introduction}

Recreational use of Salvia divinorum has become a matter of increasing concern in the United States and elsewhere, but epidemiological data from large representative 
samples are lacking to delineate the prevalence of its use across different population groups and the profiles of emerging users. ${ }^{1-8} S$. divinorum, also known as Maria Pastora, Pastora, Sage of the Seers, Diviner's Sage, Sally-D, or Magic Mint, is a perennial herb in the mint family. ${ }^{9}$ Its main active ingredient, salvinorin $\mathrm{A}$, is a kappa opioid receptor agonist and is considered one of the most potent naturally occurring hallucinogens. ${ }^{2,9-11}$ In the United States, S. divinorum and salvinorin A have no approved medical use. ${ }^{9}$ S. divinorum leaves and salvinorin A have been used to produce hallucinogenic effects. The half-life of salvinorin A in nonhuman primates is estimated to be $56.6 \pm 24.8$ minutes. ${ }^{10}$ However, the potential toxicity and metabolism of salvinorin A have not been fully investigated in laboratory animals or humans. ${ }^{10,12}$

To date, studies of $S$. divinorum have focused mainly on its effects, which have been found to be intense, shortlived, and diverse. In a study of qualitative data from 10 $S$. divinorum users collected by email interviews, Dalgarno ${ }^{13}$ found that subjective experiences due to $S$. divinorum use were quite similar to those of ketamine use. In another study of 32 recreational users of $S$. divinorum and other psychedelics, González et $\mathrm{al}^{14}$ found that smoking $S$. divinorum produced intense and short-lived psychedelic-like changes in visual perception, mood, and somatic sensations, as well as a highly modified perception of external reality and the self. Additionally, Albertson and Grubbs ${ }^{15}$ found a greater number of users who reported $S$. divinorum experiences as being more similar to those of marijuana use than to experiences produced by psychedelic mushrooms or lysergic acid diethylamide (LSD). More recently, Johnson et al ${ }^{12}$ used a controlled design to study four healthy hallucinogen-using adults and found that salvinorin A appeared to produce doserelated changes in subjective effects similar to those from use of classic hallucinogens. Recent data from a United States statewide poison control system have shown that, among patients who intentionally used $S$. divinorum, whether alone or in combination with alcohol or other drugs, psychiatric, neurologic, cardiovascular, or gastrointestinal effects were evident and that polysubstance use could result in more serious adverse effects (eg, seizures, intubations) than use of $S$. divinorum alone. ${ }^{4}$

Because of its ready availability, its legality, its hallucinogenic effects, and the lack of empirical data on long-term safety of $S$. divinorum in humans, $S$. divinorum has become a drug of increasing concern. ${ }^{1-10}$ In particular, it is easily obtained from sources that may increase exposure opportunity to psychoactive drug use. S. divinorum and salvinorin A are not currently controlled under the Controlled Substances Act in the United States, although, as of September 2010, 24 states have enacted legislation placing regulatory controls on $S$. divinorum and/or salvinorin A. ${ }^{9}$ Because it is legal to use and sell $S$. divinorum products in many jurisdictions and $S$. divinorum can be cultivated, the Internet has become one of the venues for the distribution of information about and sources of $S$. divinorum and other psychoactive substances. ${ }^{5,16}$ For example, Hoover et $\mathrm{al}^{5}$ found that many websites that sell $S$. divinorum products either encourage its use (eg, providing potentially erroneous information about the substance) or promote it as a safe or legal alternative to scheduled hallucinogens or cannabis, and that very few websites provide anti-use information. A recent study of college students found that friends and head shops serve as the primary information providers or sources of $S$. divinorum, suggesting that S. divinorum use can occur in groups. ${ }^{17}$

Moreover, although little is presently known about salvinorin A's long-term health risks in repeated users, ${ }^{10}$ case reports have demonstrated that repeated use of $S$. divinorum can be associated with serious psychiatric conditions in young or vulnerable individuals. ${ }^{2}$ For instance, Przekop and Lee ${ }^{8}$ reported on a 21-year-old man with no family or personal psychiatric history who developed persistent psychosis associated with $S$. divinorum use. Breton et $\mathrm{al}^{18}$ described a case of a bipolar 17-year-old girl who developed prolonged hallucinations and dissociative self-destructive behaviors following $S$. divinorum use. Similarly, Singh ${ }^{19}$ discussed a 15 -year-old boy with a history of $S$. divinorum and marijuana use who presented to psychiatric emergency services with acute onset of mental status changes characterized by paranoia, déjà vu, blunted affect, thought blocking, and slow speech of 3 days' duration. Together, these findings point towards a need to investigate the extent of use of this novel substance and S. divinorum users' sociodemographic, behavioral, mental health, and substance use profiles to inform research, prevention, and policy-making efforts. As noted in several research reports, epidemiological data on the prevalence of $S$. divinorum use in representative samples are lacking. 5,7,20,21

To date, there are only a few studies of prevalence and correlates of $S$. divinorum use, and they have focused primarily on college students. ${ }^{17,21,22}$ In a convenience sample of undergraduate students at a large public university in the southeastern United States ( $\mathrm{N}=825), 10.9 \%$ of men and $3.8 \%$ of women reported lifetime use of any S. divinorum; $S$. divinorum use was associated with male sex, white race, a high level of family income, marijuana use, and a low 
level of self-control. ${ }^{17,21}$ In another study of college students drawn from a large public university in the southwestern United States $(\mathrm{N}=1516)$, Lange et $\mathrm{al}^{22}$ found that $4.4 \%$ of the sample reported using $S$. divinorum at least once in the past 12 months, and that whites, males, fraternity members, illicit drug users, and heavy episodic drinkers reported a higher prevalence than other groups. However, after controlling for the other covariates in the logistic regression analysis, only past-year drug use was associated with $S$. divinorum use, suggesting drug use as a robust correlate for $S$. divinorum use. ${ }^{22}$

Of note, no studies have explored the trend in S. divinorum use despite the fact that several reports have mentioned its increasing popularity among young people. Here, we seek to address the gaps in knowledge regarding population-based prevalence estimates and correlates of $S$. divinorum use by examining prevalence rates of recent (past-year) and former (prior to the past year) $S$. divinorum use and their correlates in a large nationally representative sample of individuals aged 12 years or older. The data are drawn from multiple waves of the United States National Surveys on Drug Use and Health (NSDUH). Beginning in 2006, the NSDUH added assessments of $S$. divinorum use to the annual survey. ${ }^{23}$ In a recent NSDUH report, past-year S. divinorum use (1.7\%) among young adults aged 18-25 years in 2006 was found to be less common than past-year ecstasy use (3.8\%) but more common than past-year use of LSD (1.2\%) and phencyclidine (PCP) $(0.2 \%) .{ }^{23}$ Since the inclusion of $S$. divinorum use questions, the NSDUH data have not been utilized fully to explore changes in the prevalence of $S$. divinorum use across diverse population subgroups and correlates of use.

This study examines a geographically diverse national sample to inform recent trends in S. divinorum use (with a higher level of generalizability to population subgroups than a convenience sample) and to elucidate $S$. divinorum users' sociodemographic (age, sex, race/ethnicity, total family income, and population density of the respondent's residence), behavioral (criminal behaviors), mental health (depression, use of mental health treatment), and substance use (tobacco, alcohol, illicit or nonmedical drug use) profiles. Recent (in the past year) and former (prior to the past year) $S$. divinorum use is distinguished in the analysis to inform research and prevention efforts. These research questions have not been systematically addressed in prior NSDUH reports.

Four main questions are addressed:

1. Are there increases in $S$. divinorum use across different sociodemographic groups?
2. To what extent are sociodemographic, behavioral, mental health, and substance-use characteristics associated with recent or former $S$. divinorum use?

3. Are recent $S$. divinorum users more likely than former S. divinorum users and nonusers to have depression and substance-use disorders (nicotine, alcohol, and drug-use disorders)?

4. Among recent $S$. divinorum users, to what extent are sociodemographic, behavioral, mental health, and substance-use characteristics associated with having a substance-use disorder?

\section{Methods}

\section{Data source}

Data were from the public-use data file of the 2006-2008 NSDUH, the only survey designed to provide ongoing national estimates of substance use and disorders in the United States. ${ }^{24-26}$ The target population includes residents of households from the 50 states (including shelters, rooming houses, and group homes; civilians residing on military base) plus the District of Columbia. Participants are selected by multistage area probability methods to ensure that each independent and cross-sectional sample is representative of persons aged 12 years or older.

Respondents are interviewed privately at their places of residence. Prospective respondents are assured that their names will not be recorded and their responses will be kept strictly confidential, and all study procedures and protections are carefully explained. For adolescents aged 12-17 years, the field interviewer first seeks verbal consent from their parents/guardians. Once parental permission is granted, field interviewers then approach the adolescents and obtain their agreement to participate in the study. Parents are then asked to leave the interview setting to ensure the confidentiality of their children's responses.

The interview uses computer-assisted interviewing to increase valid reports of substance use behaviors. Sociodemographic questions are administered by interviewers using computer-assisted personal interviewing. Other questions of a sensitive nature (substance use and disorders, criminal behaviors, mental health) are administered with audio computer-assisted self-interviewing (ACASI), which provides respondents with a highly confidential means of responding to questions to increase honest reporting of sensitive behaviors. In this mode, respondents read questions on the computer screen, or questions are read to them through headphones, and they enter responses directly into a computer provided by the interviewer. 
The survey is conducted from January through December in every independent survey year. Participants are offered a US\$30 incentive for participation in the interview. In 2006-2008, approximately 67,500 unique persons aged 12 years or older were interviewed annually; weighted response rates for household screening and interviewing were $89.0 \%-90.6 \%$ and $73.9 \%-74.5 \%$, respectively. ${ }^{24-26}$ The public-use de-identified data file contains about 55,000 respondents yearly due to exclusions to ensure anonymity. In response to reports suggesting the emergence of $S$. divinorum use, specific questions about this hallucinogen were added to the survey beginning in $2006 .{ }^{23}$ This study examined data from 2006 to 2008 to determine recent national trends in $S$. divinorum use and to identify subgroups showing elevated odds of use $(\mathrm{N}=55,279$ in $2006 ; \mathrm{N}=55,435$ in 2007; $\mathrm{N}=55,739$ in 2008). The same survey items were examined across the years. Per NSDUH designs, the use of the pooled data from 3 years to examine yearly changes in prevalence rates of use is appropriate. ${ }^{24,25}$

\section{Study variables}

\section{Substance use}

NSDUH assessments of substance use were conducted via ACASI. Tobacco, alcohol, and another nine drug classes (not including $S$. divinorum) were assessed separately in 11 different sections. Each section included a detailed description of the substance class and a list of substances belonging to the class; for nonmedical use of prescription drugs, respondents were provided with pill cards showing color pictures of tablets for opioid analgesics, tranquilizers, stimulants, and sedatives. The survey asked each respondent about his/her use of each substance group and recency of use. Past-year tobacco use included use of cigarettes, chewing tobacco, snuff, dip, or pipe tobacco in the 12 months prior to the interview. Binge alcohol use was defined as drinking five or more drinks on the same occasion (ie, at the same time or within a couple of hours of each other) on at least 1 day in the past 30 days.

\section{Drug use}

Drug use included illicit use of marijuana or hashish, cocaine or crack, heroin, or hallucinogens (eg, LSD, PCP, ecstasy/3,4methylenedioxymethamphetamine [MDMA]); inhalant use (eg, nitrous oxide, amyl nitrite, cleaning fluids, gasoline, spray paint, glue); and nonmedical use of prescription analgesic opioids, stimulants (amphetamines), tranquilizers, or sedatives. Nonmedical use was defined as self-reported use of prescription drugs (pain relievers/opioids, stimulants, sedatives, and tranquilizers) that were not prescribed for the respondent or that the respondent took only for the experience or feeling they caused; use of over-the-counter drugs and legitimate use of prescription drugs were not included.

\section{S. divinorum use}

Questions about S. divinorum use were included in a separate 'Special drugs' section. Lifetime S. divinorum use was based on the following question: "Have you ever, even once, used Salvia divinorum?" Among respondents who responded affirmatively to this question, the survey then asked about recency of use: "The computer recorded that you have used Salvia divinorum. How long has it been since you last used Salvia divinorum (eg, within the past 12 months or more than 12 months ago)?" Based on responses to these two questions, we categorized respondents into three mutually exclusive groups: nonuser, past-year $S$. divinorum users (use within the past 12 months), and former users (use prior to the past 12 months).

\section{Diagnostic and Statistical Manual of Mental Disorders (DSM)-IV alcohol- or drug-use disorders (abuse, dependence)}

Respondents who reported alcohol or drug use in the past year were asked a set of structured and substance-specific questions designed to operationalize DSM-IV criteria for abuse of or dependence on each substance class in question. ${ }^{26,27}$

\section{Nicotine (cigarette) dependence}

Nicotine dependence was defined as specified by the nicotine dependence syndrome scale (NDSS) and the Fagerstrom test of nicotine dependence (FTND). ${ }^{28-30}$ NDSS questions assess dependence similar to the concepts specified by the DSM-IV, while FTND discriminates between dependent smokers and nondependent smokers by assessing how soon after waking that smokers have their first cigarette. To optimize the number of respondents classified as having current nicotine dependence, the NSDUH categorizes respondents as having nicotine dependence in the past month if they meet criteria for dependence as specified either by the NDSS or FTND. ${ }^{26}$ Past-year measurement of nicotine dependence was not available.

\section{Criminal activities and mental health}

Guided by prior research showing an association of hallucinogen use with criminality and depression, ${ }^{31-33}$ criminality, depression, and mental health treatment variables were examined as potential correlates of $S$. divinorum use. Lifetime 
criminal activity was assessed by the following question: "Not counting minor traffic violations, have you ever been arrested and booked for breaking the law?". The survey explicitly defined "being booked" as having ever been taken into custody and processed by the police or by someone connected with the courts, even if the respondent was then released. Among respondents who gave a positive response to this question, the survey then asked the number of times during the past 12 months that they had been arrested and booked.

Questions assessing major depressive episodes (MDE) were based on DSM-IV criteria and were adapted from the National Comorbidity Survey-Replication. ${ }^{26,27,34}$ A respondent was defined as having an MDE in the past year if he/she met criteria for a lifetime MDE (ie, having met at least five criteria in the same 2 -week period, in which at least one of the symptoms was a depressed mood or loss of interest or pleasure in daily activities) and had a period of time in the past 12 months when he/she felt depressed or lost interest or pleasure in daily activities for 2 weeks or longer while also having other symptoms of a lifetime MDE. ${ }^{26}$

The survey defined mental health treatment for adolescents aged 12-17 years as receiving treatment or counseling for emotional or behavioral problems from specific mental health or other health professionals in school, home, outpatient, or inpatient settings within the 12 months prior to the interview; for adults aged 18 years or older, it was defined as treatment or counseling for any problem with emotions, nerves, or mental health in the 12 months prior to the interview in any inpatient or outpatient setting, or the use of prescription medication for treatment of a mental or emotional condition. Treatment for a substance-use problem only was excluded for adolescents and adults.

\section{Sociodemographics}

Respondents' age, sex, race/ethnicity (non-Hispanic white, non-Hispanic black, Native American [American Indian/ Alaska Native], Asian/Pacific Islander/Native Hawaiian, multiple-race, Hispanic), total family income, and population density of residence were examined as potential correlates for $S$. divinorum use. ${ }^{17,21,22,31-33}$ For adolescents who were unable to respond to the income questions, proxy responses were accepted from a household member. NSDUH-defined population density was based on 2000 census data and the June 2003 Core-Based Statistical Area (CBSA) classifications, and was categorized into large metro (area with at least 1 million population), small metro (area with less than
1 million population), and nonmetropolitan (area not in a CBSA) areas.

\section{Data analysis}

The distribution of study variables by survey year were determined by $\chi^{2}$ tests. Lifetime prevalence rates of $S$. divinorum use in each year by demographic, behavioral, mental health, and substance use variables were then determined. To ease interpretation, the percentages of increase between years are reported. Next, we examined the prevalence and correlates of past-year and former use using $\chi^{2}$ and unadjusted multinomial logistic regression procedures to distinguish between characteristics of past-year users and former users as compared with nonusers. In the total sample, adjusted multinomial logistic regression analyses were then conducted to estimate the strength of associations between each covariate and $S$. divinorum use while adjusting for other variables to mitigate for their confounding effects on the estimated associations.

Finally, we determined whether past-year S. divinorum users had higher prevalence rates of depression and substance-use disorders than former users, and whether both groups had higher prevalence rates of these conditions than individuals who had never used $S$. divinorum. Adjusted logistic regression analyses also were conducted to evaluate further whether former and past-year $S$. divinorum users had greater odds of having depression and substance-use disorders than past-year alcohol or drug users who did not use $S$. divinorum and to identify subgroups of pastyear $S$. divinorum users that had elevated odds of having a substance-use disorder. All analyses were conducted with SUDAAN ${ }^{\circledR}$ to take into account NSDUH's complex designs (eg, weighting, clustering). ${ }^{35}$ All results reported here are weighted figures except for sample sizes, which are unweighted figures.

\section{Results \\ Demographic characteristics of the study sample}

There were no significant differences in the distribution of respondents' age, sex, and racial/ethnic groups across the 3 years. In the total sample $(\mathrm{N}=166,453)$, males $(49 \%)$ and females (51\%) were equally distributed; 10\% were adolescents aged $12-17$ years; $27 \%$ were young adults aged 18-34 years; and 32\% were of nonwhite race (blacks, 12\%; American Indians/Alaska Natives, 0.5\%; Asians/Pacific Islanders/Native Hawaiians, 4.5\%; multiple-race individuals, $1 \%$; Hispanics, $14 \%$ ). 


\section{Prevalence and characteristics of lifetime} S. divinorum use (Table I and Figure I)

Among individuals aged 12 years or older, 0.7\% (95\% confidence interval [CI] 0.63-0.79) reported having ever used $S$. divinorum in 2006, and the prevalence increased to $1.0 \%(95 \%$ CI $0.94-1.12)$ in 2007 and to $1.3 \%$ (95\% CI $1.19-1.42)$ in 2008.

Table 1 shows that lifetime $S$. divinorum use was associated with all study variables examined in each year $(P<0.01)$. In 2008 , comparatively high rates of lifetime use were noted among adults aged $18-25$ years $(6.1 \%)$, multiple-race individuals $(3.0 \%)$, individuals arrested for criminal activities $(7.8 \%)$, or those who had depression $(2.5 \%)$ in the past year.
Of note, $S$. divinorum use was common among individuals who used hallucinogens or stimulant drugs in the past year. Figure 1 indicates that, in 2008, lifetime $S$. divinorum use was prevalent among past-year users of LSD (53.7\%), ecstasy (30.1\%), heroin (24.2\%), PCP (22.4\%), cocaine (17.5\%), tranquilizers (15.3\%), inhalants (15.2\%), sedatives $(12.3 \%)$, opioid analgesics $(10.5 \%)$, or marijuana $(9.9 \%)$.

\section{Past-year S. divinorum users versus former $\mathrm{S}$. divinorum users (Tables 2 and 3)}

Table 2 distinguishes between past-year $S$. divinorum use and former use. Among all lifetime $S$. divinorum

Table I Lifetime prevalence of Salvia divinorum use among individuals aged 12 years or older: 2006-2008 National Surveys on Drug Use and Health $(\mathrm{N}=166,453)$

\begin{tabular}{|c|c|c|c|c|c|}
\hline $\begin{array}{l}\text { Prevalence of Salvia divinorum } \\
\text { use by study variables }\end{array}$ & 2006 & 2007 & 2008 & $\begin{array}{l}2006 \text { versus 2007: } \\
\text { increase in } \%\end{array}$ & $\begin{array}{l}2006 \text { versus 2008: } \\
\text { increase in \% }\end{array}$ \\
\hline Sample size & $N=55,279$ & $N=55,435$ & $N=55,739$ & & \\
\hline Overall prevalence, \% (SE) & $0.71(0.04)$ & $1.02(0.05)$ & $1.30(0.06)^{\mathrm{a}}$ & $44^{b}$ & $83^{b}$ \\
\hline \multicolumn{6}{|l|}{ Age group in years } \\
\hline $12-17$ & $0.88(0.09)^{\mathrm{c}}$ & $1.18(0.11)^{c}$ & $1.57(0.13)^{c}$ & 34 & $78^{\mathrm{b}}$ \\
\hline $18-25$ & $3.39(0.20)$ & $5.00(0.22)$ & $6.10(0.26)$ & $32^{\mathrm{b}}$ & $80^{\mathrm{b}}$ \\
\hline $26-34$ & $0.78(0.12)$ & $1.15(0.19)$ & $1.73(0.23)$ & 47 & $122^{\mathrm{b}}$ \\
\hline$\geq 35$ & $0.09(0.02)$ & $0.13(0.03)$ & $0.15(0.04)$ & 44 & 67 \\
\hline \multicolumn{6}{|l|}{ Sex } \\
\hline Male & $1.17(0.07)^{c}$ & $1.59(0.07)^{c}$ & $1.93(0.09)^{c}$ & $36^{b}$ & $65^{\mathrm{b}}$ \\
\hline Female & $0.27(0.03)$ & $0.49(0.04)$ & $0.71(0.06)$ & $81^{\mathrm{b}}$ & $163^{\mathrm{b}}$ \\
\hline \multicolumn{6}{|l|}{ Race/ethnicity } \\
\hline White & $0.86(0.05)^{\mathrm{c}}$ & $1.22(0.05)^{c}$ & $1.58(0.08)^{c}$ & $42^{b}$ & $84^{b}$ \\
\hline Black & $0.11(0.04)$ & $0.23(0.08)$ & $0.21(0.05)$ & 109 & 91 \\
\hline American Indian/Alaska Native & $0.68(0.48)$ & $2.04(1.26)$ & $1.18(0.35)$ & 200 & 74 \\
\hline Asian/Native Hawaiian/Pacific & $0.32(0.11)$ & $0.45(0.28)$ & $0.40(0.11)$ & 41 & 25 \\
\hline \multicolumn{6}{|l|}{ Islander } \\
\hline Multiple race & $1.18(0.39)$ & $2.35(0.6 \mathrm{I})$ & $2.95(0.8 \mathrm{I})$ & 99 & 150 \\
\hline Hispanic & $0.56(0.10)$ & $0.80(0.13)$ & $1.01(0.14)$ & 43 & 80 \\
\hline \multicolumn{6}{|l|}{ Total family income (USD) } \\
\hline$\$ 0-\$ 39,999$ & $0.85(0.06)^{c}$ & $1.20(0.08)^{d}$ & $1.61(0.10)^{c}$ & $4 I^{b}$ & $89^{b}$ \\
\hline$\$ 40,000-\$ 74,999$ & $0.56(0.06)$ & $0.82(0.08)$ & $1.15(0.10)$ & $46^{\mathrm{b}}$ & $105^{\mathrm{b}}$ \\
\hline$\geq \$ 75,000$ & $0.65(0.08)$ & $0.99(0.09)$ & $1.07(0.07)$ & $52^{\mathrm{b}}$ & $65^{\mathrm{b}}$ \\
\hline \multicolumn{6}{|l|}{ Population density of residence } \\
\hline Large metro areas & $0.75(0.06)^{c}$ & $1.03(0.07)^{c}$ & $1.22(0.08)^{c}$ & $37^{\mathrm{b}}$ & $63^{b}$ \\
\hline Small metro areas & $0.70(0.07)$ & $1.12(0.07)$ & $1.50(0.09)$ & $60^{\mathrm{b}}$ & $114^{\mathrm{b}}$ \\
\hline Nonmetro areas & $0.37(0.08)$ & $0.41(0.09)$ & $0.60(0.11)$ & 11 & 62 \\
\hline \multicolumn{6}{|c|}{ Past-year arrest for criminal activity } \\
\hline Yes & $4.75(0.59)^{c}$ & $5.75(0.66)^{c}$ & $7.80(0.75)^{c}$ & 21 & $64^{\mathrm{b}}$ \\
\hline No & $0.59(0.03)$ & $0.89(0.04)$ & $1.10(0.05)$ & $5 I^{b}$ & $86^{b}$ \\
\hline \multicolumn{6}{|l|}{ Past-year depression } \\
\hline Yes & $\mathrm{I} .44(0.20)^{\mathrm{c}}$ & $2.12(0.26)^{c}$ & $2.46(0.28)^{c}$ & 47 & $7 I^{b}$ \\
\hline No & $0.64(0.04)$ & $0.93(0.04)$ & $1.21(0.05)$ & $45^{\mathrm{b}}$ & $89^{b}$ \\
\hline \multicolumn{6}{|c|}{ Past-year mental health treatment } \\
\hline Yes & $1.05(0.11)^{c}$ & $1.56(0.14)^{c}$ & $2.01(0.19)^{c}$ & $49^{\mathrm{b}}$ & $91^{\mathrm{b}}$ \\
\hline No & $0.66(0.04)$ & $0.94(0.05)$ & $1.19(0.06)$ & $42^{\mathrm{b}}$ & $80^{b}$ \\
\hline
\end{tabular}

Notes: ${ }^{\mathrm{a}} \chi^{2}$ test $=62.15$, degrees of freedom $=2, P<0.001 ;{ }^{b} P \leq 0.05 ;{ }^{c} \chi^{2}$ test for survey year and the covariate in the first column: $P<0.00 \mathrm{I} ;{ }^{\mathrm{d}} \chi^{2}$ test for survey year and the covariate in the first column: $P<0.01$.

Abbreviation: SE, standard error. 


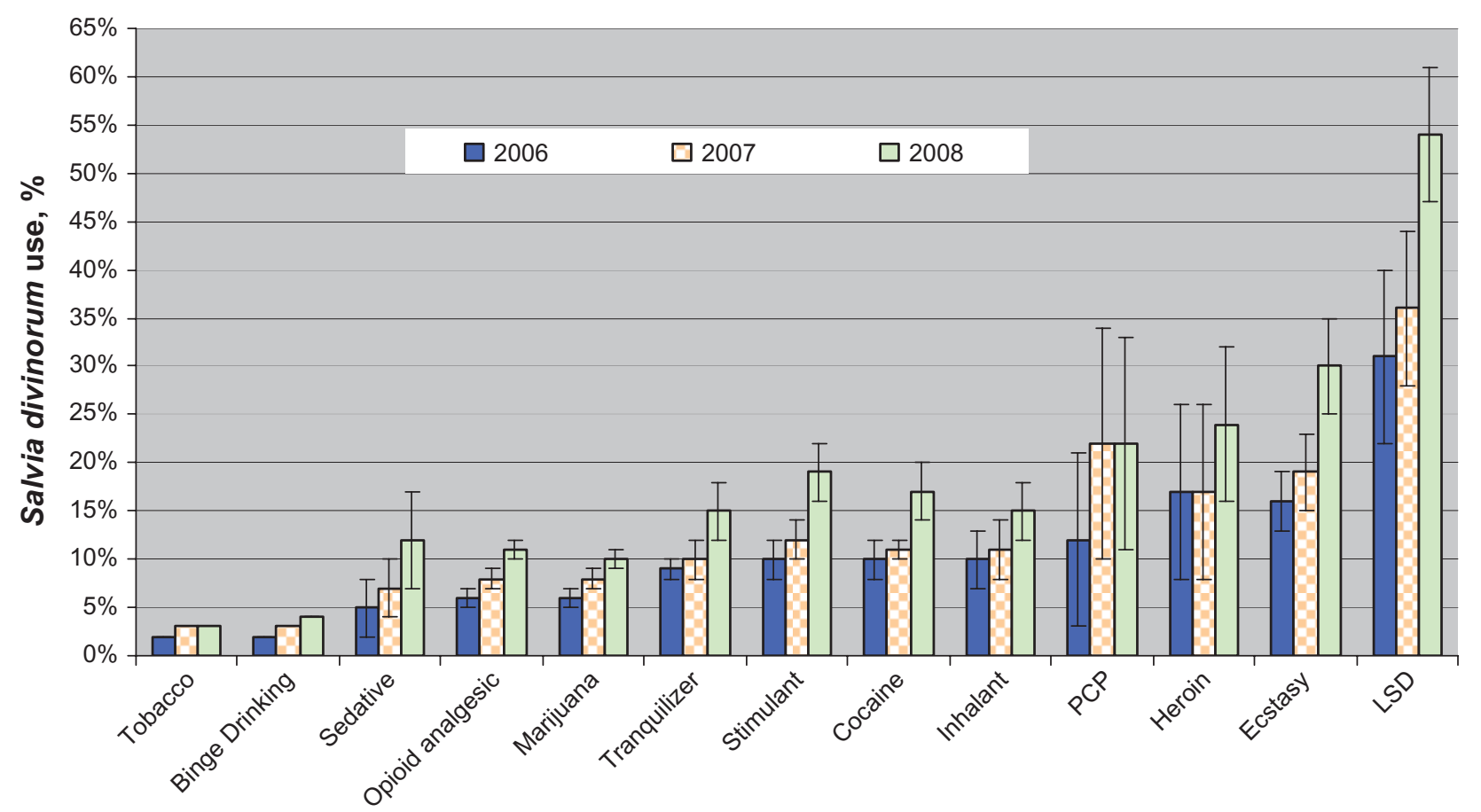

Prevalence of Salvia divinorum use among substance users

Figure I Prevalence of lifetime Salvia divinorum use among past-year substance users aged I 2 years or older by type of substance used: 2006-2008 National Surveys on Drug Use and Health $(\mathrm{N}=166,453)$. Lines extending from bars indicate $95 \%$ confidence intervals of the estimates; due to a very narrow range of $95 \%$ confidence intervals for the prevalence of lifetime Salvia divinorum use among tobacco users and binge drinkers, they are not shown in the figure.

Abbreviations: LSD, lysergic acid diethylamide; PCP, phencyclidine.

users, $40 \%$ were recent $S$. divinorum users in the past 12 months.

\section{Demographic, behavioral, and mental} health characteristics

Young adults aged $18-25$ years $(2.0 \%$ and $2.9 \%$, respectively) and individuals who were arrested for criminal activities ( $2.5 \%$ and $3.6 \%$, respectively) showed comparatively high rates of past-year use and former use, respectively (Table 2). Additional groups showing higher rates of past-year use and former use than other groups included: males $(0.6 \%, 1.0 \%)$, multiple-race individuals $(0.8 \%, 1.5 \%)$, and individuals who reported depression $(0.8 \%, 1.2 \%)$ or who received treatment for mental health problems $(0.7 \%, 0.9 \%)$ in the past year.

\section{Substance-use characteristics}

As displayed in Table 3, past-year and former use of S. divinorum were more prevalent among illicit or nonmedical drug users (3.3\%-21.3\% and 3.9\%-20.2\%, respectively) than among alcohol or tobacco users $(1.0 \%-1.2 \%$ and $1.6 \%-1.8 \%$, respectively). Specifically, users of LSD $(21.3 \%)$ had the highest prevalence of past-year $S$. divinorum use, followed by users of PCP (13.4\%), ecstasy (11.1\%), heroin $(9.8 \%)$, inhalants $(6.6 \%)$, stimulants $(6.1 \%)$, cocaine
$(5.8 \%)$, tranquilizers $(5.7 \%)$, and other drugs $(3 \%-4 \%)$. A similar pattern was noted for former use.

\section{Multinomial logistic regression of S. divinorum use (Table 4)}

Adjusted multinomial logistic regression analyses of $S$. divinorum use were conducted to estimate the strength of associations with each covariate. To account for correlations among various drug use and produce stable estimates, the 11 drug classes (marijuana, inhalants, cocaine, heroin, ecstasy, LSD, PCP, opioids, stimulants, sedatives, tranquilizers) were summed and examined as a categorical polydrug use variable in the adjusted model. The adjusted model included survey year, age, sex, race/ethnicity, annual family income, population density of residence, arrest for criminal activity, depression, mental health treatment, tobacco use, binge drinking, and polydrug use.

Adjusted analysis confirmed an increased rate of S. divinorum use in 2007 and 2008 and revealed illicit/ nonmedical drug use as the strongest correlate for either past-year or former $S$. divinorum use (Table 4). There was a graded association of past-year $S$. divinorum use with polydrug use in the past year; that is, individuals who used one drug class were about nine times more likely than 
Table 2 Demographic, behavioral, and mental health characteristics of recent (past-year) and former (prior to past year) use of Salvia divinorum among individuals aged 12 years or older: 2006-2008 National Surveys on Drug Use and Health $(\mathrm{N}=166,453)$

\begin{tabular}{|c|c|c|c|c|}
\hline $\begin{array}{l}\text { Prevalence of Salvia } \\
\text { divinorum use }\end{array}$ & $\begin{array}{l}\text { Past-year } \\
\text { use, \% (SE) }\end{array}$ & $\begin{array}{l}\text { Crude odds ratio of past-year } \\
\text { use versus never use }\end{array}$ & $\begin{array}{l}\text { Former } \\
\text { use, \% (SE) }\end{array}$ & $\begin{array}{l}\text { Crude odds ratio of former } \\
\text { use versus never use }\end{array}$ \\
\hline Overall prevalence, \% (SE) & $0.40(0.02)$ & & $0.61(0.02)$ & \\
\hline \multicolumn{5}{|l|}{ Year } \\
\hline 2006 & $0.28(0.02)$ & 1.00 & $0.42(0.03)$ & 1.00 \\
\hline 2007 & $0.41(0.03)$ & $1.46(1.21-1.77)^{\mathrm{a}}$ & $0.6 I(0.03)$ & $1.45(1.19-1.76)^{\mathrm{a}}$ \\
\hline 2008 & $0.49(0.03)$ & $1.76(1.44-2.14)^{\mathrm{a}}$ & $0.8 \mathrm{I}(0.05)$ & $1.91(1.54-2.36)^{\mathrm{a}}$ \\
\hline \multicolumn{5}{|l|}{ Age group in years } \\
\hline $12-17$ & $0.76(0.05)$ & 1.00 & $0.45(0.04)$ & 1.00 \\
\hline $18-25$ & $1.98(0.08)$ & $2.70(2.34-3.11)^{\mathrm{a}}$ & $2.85(0.10)$ & $6.62(5.48-7.99)^{\mathrm{a}}$ \\
\hline $26-34$ & $0.26(0.06)$ & $0.34(0.22-0.54)^{\mathrm{a}}$ & $0.96(0.09)$ & $2.15(1.70-2.70)^{\mathrm{a}}$ \\
\hline$\geq 35$ & $0.03(0.01)$ & $0.04(0.02-0.08)^{a}$ & $0.09(0.02)$ & $0.19(0.13-0.29)^{\mathrm{a}}$ \\
\hline \multicolumn{5}{|l|}{ Sex } \\
\hline Male & $0.62(0.03)$ & $3.29(2.76-3.91)^{\mathrm{a}}$ & $0.95(0.04)$ & $3.19(2.73-3.73)^{\mathrm{a}}$ \\
\hline Female & $0.19(0.02)$ & 1.00 & $0.30(0.02)$ & 1.00 \\
\hline \multicolumn{5}{|l|}{ Race/ethnicity } \\
\hline White & $0.47(0.02)$ & 1.00 & $0.75(0.03)$ & 1.00 \\
\hline Black & $0.08(0.02)$ & $0.17(0.10-0.28)^{\mathrm{a}}$ & $0.10(0.03)$ & $0.13(0.08-0.23)^{\mathrm{a}}$ \\
\hline American Indian/Alaska Native & $0.88(0.47)$ & $1.89(0.64-5.57)$ & $0.43(0.12)$ & $0.57(0.32-1.00)^{\mathrm{b}}$ \\
\hline Asian/Native Hawaiian/Pacific & $0.18(0.04)$ & $0.38(0.24-0.61)^{\mathrm{a}}$ & $0.21(0.09)$ & $0.28(0.12-0.67)^{c}$ \\
\hline \multicolumn{5}{|l|}{ Islander } \\
\hline Multiple race & $0.75(0.17)$ & $1.62(1.02-2.57)^{\mathrm{b}}$ & $\mathrm{I} .46(0.34)$ & $1.96(1.21-3.16)^{c}$ \\
\hline Hispanic & $0.35(0.06)$ & $0.75(0.54-1.05)$ & $0.44(0.06)$ & $0.58(0.43-0.78)^{\mathrm{a}}$ \\
\hline \multicolumn{5}{|l|}{ Total family income (USD) } \\
\hline$\$ 0-\$ 39,999$ & $0.43(0.02)$ & $1.09(0.90-1.31)$ & $0.78(0.05)$ & $1.51(1.25-1.83)^{\mathrm{a}}$ \\
\hline$\$ 40,000-\$ 74,999$ & $0.36(0.03)$ & $0.91(0.72-1.14)$ & $0.49(0.04)$ & $0.94(0.76-1.17)$ \\
\hline$\geq \$ 75,000$ & $0.39(0.03)$ & 1.00 & $0.52(0.04)$ & 1.00 \\
\hline \multicolumn{5}{|c|}{ Population density of residence } \\
\hline Large metro areas & $0.39(0.03)$ & 1.00 & $0.6 I(0.03)$ & 1.00 \\
\hline Small metro areas & $0.43(0.02)$ & $1.12(0.96-1.30)$ & $0.68(0.04)$ & I.II (0.94-I.3I) \\
\hline Nonmetro areas & $0.25(0.04)$ & $0.65(0.46-0.92)^{b}$ & $0.21(0.03)$ & $0.33(0.24-0.46)^{c}$ \\
\hline \multicolumn{5}{|c|}{ Past-year arrest for criminal activity } \\
\hline Yes & $2.51(0.22)$ & $7.93(6.47-9.71)^{\mathrm{a}}$ & $3.62(0.34)$ & $7.25(5.92-8.87)^{\mathrm{a}}$ \\
\hline No & $0.33(0.02)$ & 1.00 & $0.53(0.02)$ & 1.00 \\
\hline \multicolumn{5}{|l|}{ Past-year depression } \\
\hline Yes & $0.82(0.08)$ & $2.30(1.88-2.82)^{\mathrm{a}}$ & $1.18(0.11)$ & $2.10(1.72-2.56)^{\mathrm{a}}$ \\
\hline No & $0.36(0.02)$ & 1.00 & $0.57(0.02)$ & 1.00 \\
\hline \multicolumn{5}{|c|}{ Past-year mental health treatment } \\
\hline Yes & $0.65(0.06)$ & $1.83(1.51-2.22)^{\mathrm{a}}$ & $0.89(0.07)$ & $1.56(1.33-1.83)^{\mathrm{a}}$ \\
\hline No & $0.36(0.02)$ & 1.00 & $0.57(0.02)$ & 1.00 \\
\hline
\end{tabular}

Abbreviation: SE, standard error.

Notes: ${ }^{c} p<0.001$, ${ }^{b} P<0.01$, a $P<0.05$.

individuals who did not use any illicit/nonmedical drug in the past year to use $S$. divinorum in the past year (adjusted odds ratios [AOR] 8.95, 95\% CI 6.18-12.96). The strength of associations increased to about 19 times (AOR 18.51, 95\% CI 13.27-25.82) and 46 times (AOR 45.98, 95\% CI 32.99-64.10) for individuals who used two drug classes and three or more drug classes, respectively. A similar pattern of association, but of lesser magnitude, was noted for polydrug use and former $S$. divinorum use (AOR ranging from 6.17 to 17.36).

Adjusted analysis also showed that young adults aged 18-25 years, males, individuals who used treatment for mental health problems, and tobacco users had elevated odds of using S. divinorum in the past year, while blacks as compared with whites and those in the lowest income group as compared with those in the highest income group had decreased odds of past-year $S$. divinorum use.

Regarding former use, young adults aged 18-25 years or 26-34 years, males, residents of large or small metropolitan areas, individuals who were arrested for criminal activity recently, and tobacco users exhibited elevated odds of former S. divinorum use, while blacks, American Indians/ Alaska Natives, and Hispanics had lower odds of former use than whites. 
Table 3 Substance use characteristics of recent (past-year) and former (prior to past year) use of Salvia divinorum among individuals aged 12 years or older: 2006-2008 National Surveys on Drug Use and Health $(\mathrm{N}=166,453)$

\begin{tabular}{|c|c|c|c|c|}
\hline $\begin{array}{l}\text { Prevalence of Salvia } \\
\text { divinorum use }\end{array}$ & $\begin{array}{l}\text { Past-year } \\
\text { use, \% (SE) }\end{array}$ & $\begin{array}{l}\text { Crude odds ratio of past-year } \\
\text { use versus never use }\end{array}$ & $\begin{array}{l}\text { Former } \\
\text { use, \% (SE) }\end{array}$ & $\begin{array}{l}\text { Crude odds ratio of former } \\
\text { use versus never use }\end{array}$ \\
\hline \multicolumn{5}{|l|}{ Past-year tobacco use } \\
\hline Yes & $1.04(0.05)$ & $17.32(13.05-22.99)^{\mathrm{a}}$ & $1.56(0.06)$ & $13.27(10.79-16.32)^{\mathrm{a}}$ \\
\hline No & $0.06(0.01)$ & 1.00 & $0.12(0.01)$ & 1.00 \\
\hline \multicolumn{5}{|c|}{ Past-month binge drinking } \\
\hline Yes & $1.19(0.05)$ & $7.88(6.69-9.28)^{\mathrm{a}}$ & $1.80(0.08)$ & $7.19(6.06-8.53)^{\mathrm{a}}$ \\
\hline No & $0.16(0.01)$ & 1.00 & $0.26(0.02)$ & 1.00 \\
\hline \multicolumn{5}{|c|}{ Past-year marijuana use } \\
\hline Yes & $3.34(0.15)$ & $21.40(|6.89-27.1|)^{\mathrm{a}}$ & $4.53(0.18)$ & $10.47(8.38-13.09)^{\mathrm{a}}$ \\
\hline No & $0.06(0.01)$ & 1.00 & $0.17(0.01)$ & 1.00 \\
\hline \multicolumn{5}{|l|}{ Past-year inhalant use } \\
\hline Yes & $6.55(0.69)$ & $21.40(|6.89-27 .| I)^{\mathrm{a}}$ & $5.35(0.54)$ & $10.47(8.38-13.09)^{\mathrm{a}}$ \\
\hline No & $0.34(0.01)$ & 1.00 & $0.57(0.02)$ & 1.00 \\
\hline \multicolumn{5}{|l|}{ Past-year cocaine use } \\
\hline Yes & $5.77(0.38)$ & $24.43(20.76-28.75)^{\mathrm{a}}$ & $7.19(0.5 I)$ & $17.85(15.15-21.03)^{\mathrm{a}}$ \\
\hline No & $0.27(0.01)$ & 1.00 & $0.46(0.02)$ & 1.00 \\
\hline \multicolumn{5}{|l|}{ Past-year heroin use } \\
\hline Yes & $9.84(2.03)$ & $31.98(20.1 \mathrm{I}-50.85)^{\mathrm{a}}$ & $9.70(1.81)$ & $19.97(13.12-30.38)^{\mathrm{a}}$ \\
\hline No & $0.38(0.02)$ & 1.00 & $0.60(0.02)$ & 1.00 \\
\hline \multicolumn{5}{|l|}{ Past-year ecstasy use } \\
\hline Yes & $11.06(0.83)$ & $46.22(37.37-57.16)^{\mathrm{a}}$ & $10.67(0.92)$ & $25.66(20.61-31.96)^{\mathrm{a}}$ \\
\hline No & $0.30(0.01)$ & 1.00 & $0.53(0.02)$ & 1.00 \\
\hline \multicolumn{5}{|l|}{ Past-year LSD use } \\
\hline Yes & $21.27(1.79)$ & $107.78(84.40-137.65)^{\mathrm{a}}$ & $20.19(1.93)$ & $61.44(47.17-80.03)^{\mathrm{a}}$ \\
\hline No & $0.33(0.01)$ & 1.00 & $0.56(0.02)$ & 1.00 \\
\hline \multicolumn{5}{|l|}{ Past-year PCP use } \\
\hline Yes & $13.36(3.07)$ & $41.25(23.47-72.51)^{\mathrm{a}}$ & $4.29(1.63)$ & $8.42(3.67-19.32)^{\mathrm{a}}$ \\
\hline No & $0.39(0.02)$ & 1.00 & $0.6 \mathrm{I}(0.02)$ & 1.00 \\
\hline \multicolumn{5}{|c|}{ Past-year opioid analgesic use } \\
\hline Yes & $3.96(0.23)$ & $20.31(17.15-24.07)^{\mathrm{a}}$ & $4.36(0.25)$ & $11.26(9.37-13.06)^{\mathrm{a}}$ \\
\hline No & $0.21(0.01)$ & 1.00 & $0.42(0.02)$ & 1.00 \\
\hline \multicolumn{5}{|c|}{ Past-year stimulant use } \\
\hline Yes & $6.14(0.52)$ & $21.36(17.39-26.24)^{\mathrm{a}}$ & $7.04(0.62)$ & $14.94(12.16-18.35)^{\mathrm{a}}$ \\
\hline No & $0.33(0.01)$ & 1.00 & $0.54(0.02)$ & 1.00 \\
\hline \multicolumn{5}{|l|}{ Past-year sedative use } \\
\hline Yes & $3.63(0.61)$ & $10.06(7.02-14.42)^{\mathrm{a}}$ & $3.90(0.74)$ & $6.90(4.62-10.29)^{a}$ \\
\hline No & $0.39(0.02)$ & 1.00 & $0.60(0.02)$ & 1.00 \\
\hline \multicolumn{5}{|c|}{ Past-year tranquilizer use } \\
\hline Yes & $5.68(0.42)$ & $22.24(18.20-27.19)^{\mathrm{a}}$ & $5.95(0.42)$ & $13.27(\mid 1.19-15.74)^{\mathrm{a}}$ \\
\hline No & $0.29(0.01)$ & 1.00 & $0.50(0.02)$ & 1.00 \\
\hline
\end{tabular}

Note: ${ }^{a} P<0.001$.

Abbreviations: LSD, lysergic acid diethylamide; PCP, phencyclidine.

\section{Depression and substance use disorders among S. divinorum users (Figure 2)}

Prevalence rates of depression and all substance-use disorders (abuse or dependence) were markedly higher among past-year and former users of $S$. divinorum than among nonusers $\left(\chi^{2}\right.$, degrees of freedom $[\mathrm{df}]=2, P<0.001$ for each disorder by $S$. divinorum use status). Approximately $15 \%$ of past-year (95\% CI $11.2-19.0$ ) and $14 \%$ of former (95\% CI 11.7-16.1) S. divinorum users had self-reported depression in the past year compared with $7.2 \%$ (95\% CI 6.9-7.4) of nonusers of S. divinorum.
As summarized in Figure 2, 69.7\% of past-year S. divinorum users and $66.9 \%$ of former users had a self-reported nicotine, alcohol, or drug use disorder in the past year compared with $19.7 \%$ of nonusers. Past-year $S$. divinorum users had higher rates of alcohol and most drug use disorders (ie, any drug, alcohol, marijuana, opioid, cocaine, hallucinogen, and stimulant use disorders) than former users, but they had a similar rate of nicotine dependence and of heroin, sedative, and tranquilizer use disorders. Specifically, an estimated $43.0 \%$ of past-year 
Table $4 \mathrm{AORs}^{\mathrm{a}}$ of past-year and former (prior to past year) use of Salvia divinorum among individuals aged 12 years or older: 2006-2008 National Surveys on Drug Use and Health $(\mathrm{N}=166,453)$

\begin{tabular}{|c|c|c|}
\hline $\begin{array}{l}\text { Selected characteristics of } \\
\text { Salvia divinorum use }\end{array}$ & $\begin{array}{l}\text { Past-year Salvia divinorum } \\
\text { use versus never use } \\
\text { AOR }(95 \% \mathrm{Cl})\end{array}$ & $\begin{array}{l}\text { Former Salvia divinorum } \\
\text { use versus never use } \\
\text { AOR }(95 \% \mathrm{Cl})\end{array}$ \\
\hline \multicolumn{3}{|l|}{ Year (versus 2006) } \\
\hline 2007 & $1.66(1.36-2.03)^{\mathrm{b}}$ & $1.56(1.28-1.91)^{\mathrm{b}}$ \\
\hline 2008 & $2.19(1.78-2.70)^{\mathrm{b}}$ & $2.24(\mathrm{I} .8 \mathrm{I}-2.78)^{\mathrm{b}}$ \\
\hline \multicolumn{3}{|c|}{ Age group in years (versus $12-17$ years) } \\
\hline $18-25$ & $1.33(1.12-1.58)^{c}$ & $3.27(2.66-4.03)^{b}$ \\
\hline $26-34$ & $0.25(0.15-0.41)^{b}$ & $1.57(1.23-2.02)^{\mathrm{b}}$ \\
\hline$\geq 35$ & $0.08(0.04-0.15)^{b}$ & $0.29(0.20-0.42)^{b}$ \\
\hline \multicolumn{3}{|l|}{ Sex (versus female) } \\
\hline Male & $2.78(2.27-3.39)^{\mathrm{b}}$ & $2.58(2.16-3.07)^{\mathrm{b}}$ \\
\hline \multicolumn{3}{|l|}{ Race/ethnicity (versus white) } \\
\hline Black & $0.20(0.13-0.33)^{\mathrm{b}}$ & $0.13(0.07-0.22)^{\mathrm{b}}$ \\
\hline American Indian/Alaska Native & $1.52(0.58-3.98)$ & $0.48(0.27-0.87)^{d}$ \\
\hline Asian/Native Hawaiian/Pacific Islander & $0.71(0.44-1.13)$ & $0.43(0.17-1.09)$ \\
\hline Multiple race & $1.32(0.82-2.11)$ & $1.56(0.89-2.75)$ \\
\hline Hispanic & $0.78(0.54-1.11)$ & $0.54(0.40-0.74)^{\mathrm{b}}$ \\
\hline \multicolumn{3}{|c|}{ Total family income (USD) (versus $\$ 75,000+$ ) } \\
\hline$\$ 0-\$ 39,999$ & $0.74(0.61-0.91)^{c}$ & $1.05(0.85-1.30)$ \\
\hline$\$ 40,000-\$ 74,999$ & $0.85(0.67-1.08)$ & $0.84(0.67-1.05)$ \\
\hline \multicolumn{3}{|c|}{ Population density (versus nonmetro areas) } \\
\hline Large metro areas & $1.32(0.92-1.88)$ & $2.71(1.90-3.86)^{b}$ \\
\hline Small metro areas & $1.35(0.96-1.90)$ & $2.60(1.83-3.7 \mathrm{I})^{\mathrm{b}}$ \\
\hline \multicolumn{3}{|c|}{ Past-year arrest for criminal activity (versus no) } \\
\hline Yes & $1.14(0.91-1.42)$ & $1.28(1.03-1.60)^{d}$ \\
\hline \multicolumn{3}{|l|}{ Past-year depression (versus no) } \\
\hline Yes & $1.24(0.98-1.58)^{\mathrm{e}}$ & $1.24(0.98-1.56)^{\mathrm{e}}$ \\
\hline \multicolumn{3}{|c|}{ Past-year mental health treatment (versus no) } \\
\hline Yes & $1.33(1.06-1.67)^{d}$ & $1.21(0.99-1.49)^{f}$ \\
\hline \multicolumn{3}{|l|}{ Past-year tobacco use (versus no) } \\
\hline Yes & $2.76(2.03-3.76)^{b}$ & $2.62(2.03-3.40)^{\mathrm{b}}$ \\
\hline \multicolumn{3}{|c|}{ Past-month binge drinking (versus no) } \\
\hline Yes & $1.16(0.93-1.44)$ & $1.19(0.97-1.46)$ \\
\hline \multicolumn{3}{|c|}{ Past-year polydrug use, number of the II drug classes used in the past yearg (versus none) } \\
\hline 1 & $8.95(6.18-12.96)^{b}$ & $6.17(4.81-7.90)^{b}$ \\
\hline 2 & $18.5 \mid(\mid 3.27-25.82)^{\mathrm{b}}$ & $9.08(6.86-12.02)^{\mathrm{b}}$ \\
\hline$\geq 3$ & $45.98(32.99-64.10)^{\mathrm{b}}$ & $17.36(|3.5|-22.31)^{b}$ \\
\hline
\end{tabular}

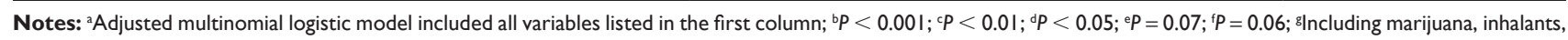
cocaine, heroin, ecstasy/MDMA, LSD, PCP, analgesic opioids, stimulants, sedatives, and tranquilizers.

Abbreviations: AOR, adjusted odds ratio; Cl, confidence interval; LSD, lysergic acid diethylamide; MDMA, 3,4-methylenedioxymethamphetamine (ecstasy); PCP, phencyclidine.

users and $28.9 \%$ of former users had a drug-use disorder compared with only $2.5 \%$ of nonusers of $S$. divinorum. Alcohol (42.8\%, 35.8\%, respectively), marijuana (33.0\%, $21.5 \%$, respectively), nicotine (31.0\%, $36.1 \%$, respectively), opioid $(10.5 \%, 6.0 \%$, respectively), and cocaine (10.5\%, $5.0 \%$, respectively) use disorders were comparatively common among past-year and former users of S. divinorum, respectively. Prevalence rates of these disorders, however, were comparatively low among nonusers of $S$. divinorum $(0.6 \%-13.8 \%)$.

\section{Logistic regression of depression} and substance use disorders among S. divinorum users compared with other substance users (Table 5)

Adjusted logistic regression analyses were conducted to determine whether $S$. divinorum users were more likely than other substance users to have depression or a substanceuse disorder. Table 5 shows that former and past-year S. divinorum users were about 1.4 times more likely than pastyear alcohol or drug users who did not use S. divinorum to 


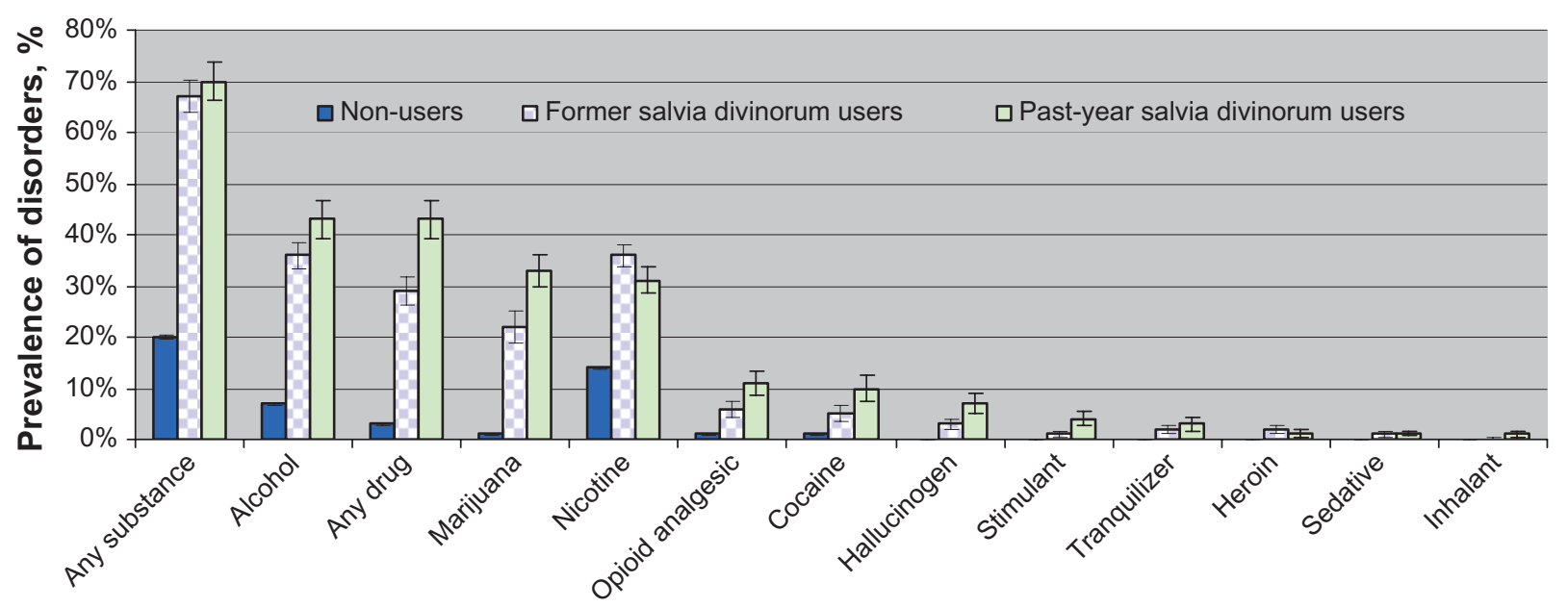

Prevalence of substance use disorders by Salvia divinorum use status

Figure 2 Prevalence of substance use disorders (abuse or dependence) among past-year and former (prior to the past 12 months) users of Salvia divinorum compared with nonusers aged 12 years or older: 2006-2008 National Surveys on Drug Use and Health $(N=166,453)$. $\chi^{2}$ (degrees of freedom $=2$ ) $P<0.00$ I for each disorder by Salvia divinorum use status. Any drug abuse or dependence included abuse of or dependence on marijuana, inhalants, cocaine, heroin, hallucinogens, opioid analgesics, stimulants, sedatives, and tranquilizers in the past year. Except for nicotine dependence, which refers to dependence in the past month, all other substance use disorders include abuse of or dependence on that substance class in the past year. Lines extending from bars indicate $95 \%$ confidence intervals of the estimates; due to a very narrow range of $95 \%$ confidence intervals for nonusers, they are not shown in the figure.

have depression in the past year. Both groups of $S$. divinorum users also were about 3-4 times more likely than past-year alcohol or drug users who did not use $S$. divinorum to have an alcohol or drug-use disorder in the past year.

\section{Logistic regression of substance-use disorders among S. divinorum users (Table 6)}

Finally, adjusted logistic regression analyses were conducted to identify subgroups of past-year $S$. divinorum users that had elevated odds of having a substance-use disorder (Table 6). Among past-year $S$. divinorum users $(\mathrm{N}=1585)$ : young adults aged 26-34 years, low- and middle-level income groups, individuals who were arrested for criminal activities or who had depression, and binge drinkers had elevated odds of nicotine dependence; depression, use of mental health treatment, and binge drinking increased odds of having an alcohol-use disorder; and American Indian/Alaska Native race, being arrested for criminal activity, depression, use of mental health treatment, tobacco use, and binge drinking increased odds of having a drug-use disorder.

\section{Discussion Main findings}

This study of a large nationally representative sample documents a significant increase in $S$. divinorum use, identifies several groups showing elevated odds of $S$. divinorum use, and provides a comprehensive profile of substance-use disorders for $S$. divinorum users. These findings are useful to concerned citizens and health professionals, and have implications for prevention and research efforts. First, over a 3-year period, the prevalence of $S$. divinorum use nationally

Table 5 AORs of depression and substance-use disorders among Salvia divinorum users compared with alcohol or drug users who did not use Salvia divinorum in the past year: 2006-2008 National Surveys on Drug Use and Health $(\mathrm{N}=106,042)$

\begin{tabular}{lll}
\hline Substance use status & $\begin{array}{l}\text { AOR of depression' } \\
(\mathbf{9 5 \%} \mathbf{C l})\end{array}$ & $\begin{array}{l}\text { AOR of alcohol or drug use disorders' } \\
(\mathbf{9 5 \%} \mathbf{C l})\end{array}$ \\
\hline Former Salvia divinorum users & $1.44(\mathrm{I} .13-1.82) P<0.01$ & $2.97(2.54-3.48) P<0.01$ \\
Past-year Salvia divinorum users & $1.45(1.12-1.88) P<0.01$ & $4.33(3.55-5.29) P<0.01$ \\
Past-year alcohol or drug users & 1.00 & 1.00 \\
who did not use Salvia divinorum ${ }^{2}$ & &
\end{tabular}

Notes: 'The adjusted logistic regression model controlled for survey year, age, sex, race/ethnicity, population density, arrests for criminal activity, and mental heath treatment; ${ }^{2}$ Including past-year users of alcohol, marijuana, inhalants, cocaine, heroin, ecstasy, LSD, PCP, analgesic opioids, stimulants, sedatives, and tranquilizers.

Abbreviations: AOR, adjusted odds ratio; Cl, confidence interval; LSD, lysergic acid diethylamide; PCP, phencyclidine. 
Table 6 AORs $s^{\mathrm{a}}$ of substance use disorders among past-year Salvia divinorum users aged 12 years or older: 2006-2008 National Surveys on Drug Use and Health $(\mathrm{N}=1585)$

\begin{tabular}{|c|c|c|c|}
\hline $\begin{array}{l}\text { Selected characteristics of } \\
\text { Salvia divinorum users }\end{array}$ & $\begin{array}{l}\text { AOR of nicotine dependence } \\
(95 \% \mathrm{Cl})\end{array}$ & $\begin{array}{l}\text { AOR of alcohol use disorders } \\
(95 \% \mathrm{Cl})\end{array}$ & $\begin{array}{l}\text { AOR of drug use disorders } \\
(95 \% \mathrm{Cl})\end{array}$ \\
\hline \multicolumn{4}{|l|}{ Year (versus 2006) } \\
\hline 2007 & $1.13(0.76-1.67)$ & $0.95(0.64-I .4 I)$ & $0.85(0.53-1.37)$ \\
\hline 2008 & I.0I (0.69-1.50) & $1.22(0.84-1.75)$ & $1.03(0.68-1.56)$ \\
\hline \multicolumn{4}{|l|}{ Age group (versus $12-17$ years) } \\
\hline $18-25$ & I.06 (0.74-I.52) & $1.07(0.74-1.57)$ & $0.73(0.5 \mathrm{I}-1.05)$ \\
\hline $26-34$ & $2.80(1.20-6.55)^{\mathrm{b}}$ & $1.48(0.57-3.80)$ & $0.73(0.30-1.80)$ \\
\hline$\geq 35$ years & $1.15(0.79-1.68)$ & $1.27(0.30-5.26)$ & $0.59(0.21-1.66)$ \\
\hline \multicolumn{4}{|l|}{ Sex (versus female) } \\
\hline Male & I. $15(0.79-1.68)$ & $0.88(0.58-1.34)$ & $1.05(0.73-1.52)$ \\
\hline \multicolumn{4}{|l|}{ Race/ethnicity (versus white) } \\
\hline Black & $0.65(0.18-2.32)$ & $1.10(0.37-3.28)$ & $2.06(0.7 I-5.97)$ \\
\hline American Indian/Alaska Native & $0.18(0.03-1.05)$ & $0.70(0.19-2.66)$ & $14.63(2.20-97.15)^{c}$ \\
\hline Asian/Native Hawaiian/Pacific Islander & $1.15(0.45-2.91)$ & I. $18(0.38-3.68)$ & $0.66(0.24-1.84)$ \\
\hline Multiple race & $1.21(0.55-2.66)$ & $1.94(0.79-4.76)$ & $1.26(0.62-2.58)$ \\
\hline Hispanic & $0.85(0.44-1.63)$ & $0.71(0.37-1.36)$ & $0.77(0.39-1.50)$ \\
\hline \multicolumn{4}{|c|}{ Total family income (USD) (versus $\$ 75,000+$ ) } \\
\hline$\$ 0-\$ 39,999$ & $1.55(1.03-2.34)^{\mathrm{b}}$ & $0.86(0.55-1.36)$ & $1.05(0.65-1.70)$ \\
\hline$\$ 40,000-\$ 74,999$ & $1.56(1.10-2.20)^{\mathrm{b}}$ & $1.01(0.63-1.62)$ & $0.96(0.60-1.53)$ \\
\hline \multicolumn{4}{|c|}{ Population density (versus nonmetro) } \\
\hline Large metro areas & $0.91(0.47-1.79)$ & $1.12(0.45-2.81)$ & $1.10(0.45-2.66)$ \\
\hline Small metro areas & $1.10(0.55-2.21)$ & $1.31(0.54-3.16)$ & $1.08(0.49-2.37)$ \\
\hline \multicolumn{4}{|c|}{ Arrested for criminal activity (versus no) } \\
\hline Yes & $2.06(1.27-3.34)^{c}$ & $1.51(0.95-2.40)$ & $1.85(1.25-2.73)^{c}$ \\
\hline \multicolumn{4}{|l|}{ Past-year depression (versus no) } \\
\hline Yes & $1.85(1.15-2.99)^{\mathrm{b}}$ & $1.76(1.05-2.93)^{\mathrm{b}}$ & $2.24(1.32-3.83)^{c}$ \\
\hline \multicolumn{4}{|c|}{ Mental health treatment (versus no) } \\
\hline Yes & $1.22(0.77-1.92)$ & $1.17(0.72-1.91)^{b}$ & $2.97(1.91-4.62)^{d}$ \\
\hline \multicolumn{4}{|l|}{ Current tobacco use (versus no) } \\
\hline Yes & $-^{\mathrm{e}}$ & $1.35(0.70-2.58)$ & $2.01(1.07-3.77)^{\mathrm{b}}$ \\
\hline \multicolumn{4}{|l|}{ Binge drinking (versus no) } \\
\hline Yes & $\mathrm{I} .65(1.1 \mathrm{I}-2.45)^{\mathrm{b}}$ & $7.87(5.16-12.02)^{d}$ & $1.72(1.13-2.62)^{\mathrm{b}}$ \\
\hline
\end{tabular}

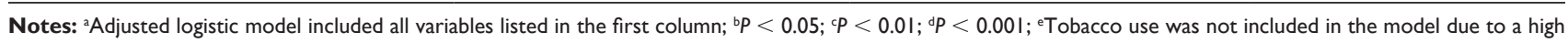
level of correlation.

Abbreviations: AOR, adjusted odds ratio; $\mathrm{Cl}$, confidence interval.

had increased moderately, suggesting a need to monitor the trend in $S$. divinorum use. Females, individuals with middle-level family income (US\$40,000-US\$74,999), and residents of small metropolitan areas showed a substantial ( $>100 \%$ ) increase in use. Second, while $S$. divinorum use in the general population is infrequent, young adults aged 18-25 years and individuals who were arrested for criminal activity had a disproportionally high rate of lifetime and recent use. Third, S. divinorum use was particularly common among past-year users of hallucinogens or stimulants, and the odds of past-year use increased with polydrug use, suggesting that polydrug users who used hallucinogens or stimulants have an increased probability of using S. divinorum. Fourth, the majority of former (70\%) and past-year (67\%) S. divinorum users were affected by symptoms of nicotine, alcohol, or drug-use disorders in the past year, and past-year S. divinorum users (especially binge drinkers and individuals with depression or other mental health problems) manifested the most problems related to alcohol and drug-use disorders. Adjusted analysis helps to reveal that either former or pastyear S. divinorum users were more likely than past-year substance users who did not use $S$. divinorum to have depression or a substance-use disorder in the past year.

\section{What this study adds}

This study represents the first effort to examine recent trends in the prevalence of $S$. divinorum use. Previous studies of prevalence or correlates of $S$. divinorum use have relied on convenience samples, and some findings are constrained by a small sample. ${ }^{17,21,22,36}$ State-level variations in legal status 
of $S$. divinorum use also might influence the access to or use of $S$. divinorum, resulting in regional variations in use. Of note, results from these NSDUH data, which include a large probability sample from all 50 states plus the District of Columbia, delineate recent changes in S. divinorum use across diverse age, sex, and racial/ethnic groups. Findings reveal a significant $83 \%$ increase within a 3 -year period, and an increase was noted across different sex and income groups, suggesting that this increase is robust. These findings are in line with results from studies on $S$. divinorum use among YouTube users, S. divinorum and salvinorin A seized data, and Internet access to $S$. divinorum, which have indirectly suggested the rising popularity in use of $S$. divinorum. , $37,38^{5}$

The findings also are consistent with recent results from studies of college students showing that whites, males, and individuals of a higher level of family income have an elevated rate of $S$. divinorum use. 17,21,22 Additionally, with these national data, we found that residents of metropolitan areas, individuals who were arrested for criminal activities, and individuals with depression or who use treatment for mental health problems have increased odds of recent $S$. divinorum use. These findings suggest some regional variations in $S$. divinorum use and show that $S$. divinorum users, like users of other hallucinogens and substance users in general, have a higher likelihood of exhibiting externalizing or internalizing problems than nonusers of $S$. divinorum. ${ }^{31-33}$ Moreover, because $S$. divinorum use was robustly associated with other drugs connected with use in group settings, ${ }^{31}$ such as ecstasy and LSD (http://www.clubdrugs.gov/), one possibility is raised that $S$. divinorum is being used in groups. ${ }^{17}$ Given that $S$. divinorum's subjective effects are reportedly similar to those of marijuana, LSD, and ketamine, ${ }^{13-15}$ research is warranted to explore the context of $S$. divinorum use and to assess health risks associated with its use in conjunction with other substances (eg, risk for intoxication, accidents, injuries, psychiatric events, and overdose). 1,2,4,8,11,19

Furthermore, multiple-race individuals were the only group in the adjusted model that showed greater odds of both recent and former $S$. divinorum use than whites. Prior research on club drug use (ie, use of methamphetamine, ecstasy, LSD, ketamine, gamma hydroxybutyrate, or flunitrazepam; http://www.clubdrugs.gov/) among youth aged 16-23 years also found a high prevalence of lifetime club drug use (29\%) among multiple-race youth compared with $24 \%$ of whites or American Indians/Alaska Natives and $5 \%-15 \%$ of other racial/ethnic groups. ${ }^{31}$ Thus, in addition to whites and young adults, multiple-race groups need research to explore contextual and psychological factors that may promote their use of $S$. divinorum and other hallucinogenic or stimulant drugs.

Additional research also is recommended to monitor S. divinorum use among females (eg, young white females), as they demonstrate the highest level of increase (163\%). Although the majority of $S$. divinorum users were males, recent results from an online survey of self-identified $S$. divinorum users $(\mathrm{N}=219)$ showed that females were about twice as likely than males to be in the young age group ( $<22$ years) ${ }^{36}$ Possible research efforts might explore whether ease of access, legal status, use of club drugs, and the perception of $S$. divinorum as a legal or safer alternative to illicit drugs promote experimentation or continued use of S. divinorum. . $^{5-7,39}$

Lastly, these findings reveal that $S$. divinorum is most likely to be used by active illicit drug users, particularly substance users who have used hallucinogenic or stimulant drugs, and that the vast majority of $S$. divinorum users were affected by symptoms and consequences indicative of substance use problems (eg, role interference, use in hazardous conditions that increase risk for injuries, physical dependence on substances, compulsive drug use or seeking behaviors, repeated substance use despite having substance-related health problems). $S$. divinorum users also have a higher rate of depression than nonusers, and $S$. divinorum users who had depression or used treatment for mental health problems were particularly more likely than those without mental health conditions to have alcohol or drug-use disorders. Therefore, repeated S. divinorum use for the purpose of "getting high" or "obtaining hallucinogenic effects" could pose a health concern (eg, drug interaction, intoxication) or increase the likelihood of medical and other psychiatric conditions for subsets of users who have been affected by other substance use or psychiatric disorders. . $^{2,4,8,18,19}$

\section{Limitations and strengths}

These findings should be interpreted with caution. NSDUH uses a cross-sectional design and relies on self-reports, which can be influenced by memory error and underreporting. All results are considered estimates, and no causal inference can be drawn. For example, the causal relation between substance use and depression cannot be determined by the NSDUH data. Study findings also are limited by the lack of data on contextual factors associated with $S$. divinorum use, motives or detailed frequency of use, and $S$. divinorum-specific problems. Studies of con- 
venience samples of $S$. divinorum users have suggested that $S$. divinorum was used for a variety of reasons (eg, for fun, curiosity, social purposes, drug-induced states of consciousness, getting high, self-defined spiritual purposes, relieving boredom, reducing medical or psychological problems) and that a very small subset of users were frequent users. ${ }^{36,40,41}$ However, these results from small or convenience samples need to be confirmed and extended using data from surveys of a probability sample or controlled studies. ${ }^{36,40,41}$ In addition, NSDUH assessments of substance-use disorders and major depression are based on standardized questions designed to operationalize DSM-IV criteria for these disorders. These results are self-reported, survey-based estimates and not clinical diagnoses (ie, not being validated by clinicians). Moreover, because of a lack of research data, there are no established criteria for assessing abuse of or dependence on $S$. divinorum..$^{27}$ Results from this study also are not applicable to institutionalized and homeless individuals because these groups are not included in the NSDUH sampling.

Nonetheless, NSDUH has noteworthy strengths not available in small-scale studies. NSDUH is the first national United States survey to add $S$. divinorum use questions to the assessment beginning in 2006. ${ }^{23}$ Because $S$. divinorum and salvinorin $\mathrm{A}$ are not controlled substances under the Controlled Substances Act in the United States and have no approved medical use, there is a scarcity of data about their use and adverse effects. ${ }^{38}$ For example, the annual reports of the American Association of Poison Control Centers (AAPCC), IMS National Prescription Audit Plus ${ }^{\mathrm{TM}}$ (a database of prescription drugs), the Aggregate Production Quota (a database for the maximum amount of Schedule I and II substances manufactured in the United States), and the ongoing United States Drug Abuse Warning Network (DAWN) reports have not included data on use and problems associated with $S$. divinorum and salvinorin A. ${ }^{38}$ Given the lack of data, this study makes a timely and unique contribution by presenting the most recent national trends in $S$. divinorum use and by documenting a comprehensive profile of substance-use problems among $S$. divinorum users.

These findings also have a higher level of generalizability to population subgroups than those of a convenience or regional sample due to the large representative sample consisting of geographically diverse racial/ethnic groups. Lastly, the survey has high levels of response rates for household screening and interviewing, uses the most sophisticated survey methods available to improve respondents' honest reporting of substance-use behaviors (ie, computer-assisted self-administered interviewing and anonymous data collection), includes detailed probes and color pictures of prescription drugs to facilitate assessments for substance use behaviors, and applies the 2000 census to improve sample weight calibration. ${ }^{24-26}$

\section{Conclusion and implications}

Nationally, the rate of $S$. divinorum use has increased moderately. While young adults aged 18-25 years show an elevated likelihood of recent $S$. divinorum use, $S$. divinorum is most likely to be used by recent or active drug users who have used hallucinogens or stimulants. Polydrug use is the most robust determinant of $S$. divinorum use. S. divinorum users who engaged in binge drinking, experienced depression, or used treatment for mental health problems had particularly high odds of having substance use disorders. The high prevalence of past-year substance use disorders among recent $S$. divinorum users emphasizes the need for research to address several open issues for $S$. divinorum use, including its addictive potential, its influence on continuance of druguse behaviors or escalation to addiction (eg, as an alternative to other drugs, cross-tolerance), adverse effects from drug interactions (eg, intoxications, accidents, injuries, health risk), and long-term effects on human health. ${ }^{1,2,4,8,10,39}$ Health care professionals and individuals involved in substance abuse care or services need to be aware of this new drug. ${ }^{39}$ Assessments of recreational $S$. divinorum use need to be improved and considered for addition to the clinical assessment for addiction problems. Finally, continuous surveillance of $S$. divinorum use among high-risk groups is warranted.

\section{Acknowledgments}

This article was supported primarily by research grants from the US National Institute on Drug Abuse of the National Institutes of Health (R01DA019623, R33DA027503, and R01DA019901 to L-T Wu). GE Woody was supported by K05DA017009 and U10DA013043. J-H Li was supported by the Committee on Chinese Medicine and Pharmacy (CCMP100-CP-006) and the Food and Drug Administration (DOH100-FDA-61402) of the Department of Health, Taiwan. Its contents are solely the responsibility of the authors and do not necessarily represent the official views of the National Institutes of Health. The Substance Abuse and Mental Health Data Archive provided the public use data files for NSDUH, which was sponsored by the Office of Applied Studies of the Substance Abuse and Mental Health Services Administration. We thank Amanda McMillan for her editorial assistance. 


\section{Ethical approval}

This work was approved by the Duke University Institutional Review Board.

\section{Disclosure}

GE Woody is a member of the RADARS post-marketing study external advisory group, whose job is to assess abuse of prescription medications. Denver Health administers RADARS, and nine pharmaceutical companies currently support its work. The other authors have no conflicts of interest to disclose.

\section{References}

1. Babu KM, McCurdy CR, Boyer EW. Opioid receptors and legal highs: Salvia divinorum and Kratom. Clin Toxicol (Phila). 2008;46(2): 146-152.

2. Bücheler R, Gleiter CH, Schwoerer P, Gaertner I. Use of non-prohibited hallucinogenic plants: increasing relevance for public health? A case report and literature review on the consumption of Salvia divinorum (Diviner's Sage). Pharmacopsychiatry. 2005;38(1):1-5.

3. Prosser JM, Nelson LS. Trends in adolescent drug abuse. Emerg Med. 2008;40(5):8. Available from: http://www.emedmag.com/html/pre/fea/ features/040050008.asp.

4. Vohra R, Seefeld A, Cantrell FL, Clark RF. Salvia divinorum: exposures reported to a statewide poison control system over 10 years. J Emerg Med. Epub 2009 Sep 16.

5. Hoover V, Marlowe DB, Patapis NS, Festinger DS, Forman RF. Internet access to Salvia divinorum: implications for policy, prevention, and treatment. J Subst Abuse Treat. 2008;35(1):22-27.

6. Giroud C, Felber F, Augsburger M, Horisberger B, Rivier L, Mangin P. Salvia divinorum: an hallucinogenic mint which might become a new recreational drug in Switzerland. Forensic Sci Int. 2000;112(2-3): $143-150$

7. Griffin $\mathrm{OH}$, Miller BL, Khey DN. Legally high? Legal considerations of Salvia divinorum. J Psychoactive Drugs. 2008;40(2):183-191.

8. Przekop P, Lee T. Persistent psychosis associated with Salvia divinorum use. Am J Psychiatry. 2009;166(7):832.

9. Drug Enforcement Administration. Salvia divinorum and salvinorin A Washington, DC: Office of Diversion Control, Drug and Chemical Evaluation Section; December 2010. Available from: http://www.deadiversion. usdoj.gov/drugs_concern/salvia_d.pdf. Accessed February 14, 2011.

10. Prisinzano TE. Psychopharmacology of the hallucinogenic sage Salvia divinorum. Life Sci. 2005;78(5):527-531.

11. Valdés LJ 3rd. Salvia divinorum and the unique diterpene hallucinogen, Salvinorin (divinorin) A. J Psychoactive Drugs. 1994;26(3): 277-283.

12. Johnson MW, Maclean KA, Reissig CJ, Prisinzano TE, Griffiths RR. Human psychopharmacology and dose-effects of salvinorin A, a kappa opioid agonist hallucinogen present in the plant Salvia divinorum. Drug Alcohol Depend. Epub 2010 Dec 4.

13. Dalgarno P. Subjective effects of Salvia divinorum. J Psychoactive Drugs. 2007;39(2):143-149.

14. González D, Riba J, Bouso JC, Gómez-Jarabo G, Barbanoj MJ. Pattern of use and subjective effects of Salvia divinorum among recreational users. Drug Alcohol Depend. 2006;85(2):157-162.

15. Albertson DN, Grubbs LE. Subjective effects of Salvia divinorum: LSD- or marijuana-like? J Psychoactive Drugs. 2009;41(3):213-217.

16. Halpern JH, Pope HG Jr. Hallucinogens on the Internet: a vast new source of underground drug information. Am J Psychiatry. 2001;158(3): 481-483.

17. Khey DN, Miller BL, Griffin OH. Salvia divinorum use among a college student sample. J Drug Educ. 2008;38(3):297-306.
18. Breton JJ, Huynh C, Raymond S, et al. Prolonged hallucinations and dissociative self mutilation following use of Salvia divinorum in a bipolar adolescent girl. J Subst Use. 2010;(15)2:113-117.

19. Singh S. Adolescent salvia substance abuse. Addiction. 2007;102(5): 823-824.

20. Babu K, Boyer EW, Hernon C, Brush DE. Emerging drugs of abuse. Clin Pediatr Emerg Med. 2005;6(2);81-84.

21. Miller BL, Griffin H III, Gibson CL, Khey DN. Trippin' on Sally D: exploring predictors of Salvia divinorum experimentation. J Crim Justice. 2009;37:396-403.

22. Lange JE, Reed MB, Croff JM, Clapp JD. College student use of Salvia divinorum. Drug Alcohol Depend. 2008;94(1-3):263-266.

23. Substance Abuse and Mental Health Services Administration. The NSDUH report: use of specific hallucinogens. Rockville, MD: Substance Abuse and Mental Health Services Administration, Office of Applied Studies; 2006.

24. Substance Abuse and Mental Health Services Administration. Results from the 2006 National Survey on Drug Use and Health: national findings (DHHS Publication No. SMA 07-4293, NSDUH Series H-32). Rockville, MD: Substance Abuse and Mental Health Services Administration, Office of Applied Studies; 2007.

25. Substance Abuse and Mental Health Services Administration. Results from the 2007 National Survey on Drug Use and Health. Rockville, MD: Substance Abuse and Mental Health Services Administration, Office of Applied Studies; 2008.

26. Substance Abuse and Mental Health Services Administration. Results from the 2008 National Survey on Drug Use and Health. Rockville, MD: Substance Abuse and Mental Health Services Administration, Office of Applied Studies; 2009.

27. American Psychiatric Association. Diagnostic and Statistical Manual of Mental Disorders. 4th ed, text rev. Washington, DC: American Psychiatric Publishing, Inc.; 2000.

28. Shiffman S, Waters A, Hickcox M. The Nicotine Dependence Syndrome Scale: a multidimensional measure of nicotine dependence. Nicotine Tob Res. 2004;6(2):327-348.

29. Fagerstrom KO. Measuring degree of physical dependence to tobacco smoking with reference to individualization of treatment. Addict Behav. 1978;3(3-4):235-241.

30. Heatherton TF, Kozlowski LT, Frecker RC, Fagerström KO. The Fagerström Test for Nicotine Dependence: a revision of the Fagerström Tolerance Questionnaire. Br J Addict. 1991;86(9):1119-1127.

31. Wu LT, Schlenger WE, Galvin DM. Concurrent use of methamphetamine, MDMA, LSD, ketamine, GHB, and flunitrazepam among American youths. Drug Alcohol Depend. 2006;84(1): $102-113$.

32. Wu LT, Ringwalt CL, Mannelli P, Patkar AA. Hallucinogen use disorders among adult users of MDMA and other hallucinogens. Am J Addict. 2008;17(5):354-363.

33. Wu LT, Ringwalt CL, Weiss RD, Blazer DG. Hallucinogen-related disorders in a national sample of adolescents: the influence of ecstasy/ MDMA use. Drug Alcohol Depend. 2009;104(1-2):156-166.

34. Kessler RC, Birnbaum H, Bromet E, Hwang I, Sampson N, Shahly V. Age differences in major depression: results from the National Comorbidity Survey Replication (NCS-R). Psychol Med. 2010;40(2): 225-237.

35. Research Triangle Institute. SUDAAN User's Manual, Release 9.0. Research Triangle Park, NC: Research Triangle Institute; 2006.

36. Nyi PP, Lai EP, Lee DY, Biglete SA, Torrecer GI, Anderson IB. Influence of age on Salvia divinorum use: results of an Internet survey. J Psychoactive Drugs. 2010;42(3):385-392.

37. Lange JE, Daniel J, Homer K, Reed MB, Clapp JD. Salvia divinorum: effects and use among YouTube users. Drug Alcohol Depend. 2010;108: $138-140$.

38. Drug Enforcement Administration. Salvia divinorum and salvinorin A. Drug fact sheet. Washington, DC: Drug Enforcement Administration, Office of Diversion Control, Drug and Chemical Evaluation Section; 2010 . 
39. Richardson WH 3rd, Slone CM, Michels JE. Herbal drugs of abuse: an emerging problem. Emerg Med Clin North Am. 2007;25(2):435-457.

40. Baggott MJ, Erowid E, Erowid F, Galloway GP, Mendelson J. Use patterns and self-reported effects of Salvia divinorum: an Internet-based survey. Drug Alcohol Depend. 2010;111(3):250-256.
41. Sumnall HR, Measham F, Brandt SD, Cole JC. Salvia divinorum use and phenomenology: results from an online survey. J Psychopharmacol. Epub 2010 Oct 11.

\section{Publish your work in this journal}

Substance Abuse and Rehabilitation is an international, peer-reviewed, open access journal publishing original research, case reports, editorials, reviews and commentaries on all areas of addiction and substance abuse and options for treatment and rehabilitation. The manuscript management system is completely online and includes a very quick and fair peer-review system. Visit http://www.dovepress.com/testimonials. php to read real quotes from published authors.

Submit your manuscript here: http://www.dovepress.com/substance abuse-and-rehabilitation-journal 